\title{
FUNCIONAMENTO DE UMA DISCIPLINA DE QUÍMICA GERAL EM UM CURSO TÉCNICO SEMIPRESENCIAL
}

\author{
L.S. RODRIGUES ${ }^{1}$, A.A.M. MACEDO ${ }^{2}$, M.V.P. LOPES $^{3}$ \\ Universidade Federal do Maranhão ${ }^{1,2}$ \\ Instituto Federal de Educação, Ciência e Tecnologia do Ceará ${ }^{3}$ \\ leorodrigues4@hotmail.com ${ }^{1}$
}

Artigo submetido em 11/09/2018 e aceito em 16/01/2020

DOI: $10.15628 /$ holos.2019.7725

\section{RESUMO}

A educação a distância trouxe diversos impactos positivos devido à ampliação e acessibilidade ao ensino, pois aluno e professor não precisariam estar presentes no mesmo local físico para que a troca de saberes acontecesse. Dessa forma, este estudo busca comparar duas matrizes curriculares de ensino do curso técnico em Química na modalidade presencial e semipresencial, além de verificar quantitativamente a participação dos tutores em fóruns virtuais de aprendizagem. Como recurso metodológico selecionou-se uma instituição de ensino pública que ofertasse o curso Técnico em Química tanto na modalidade presencial como na modalidade semipresencial. Após analisar os dados é possível perceber que o curso Técnico em Química na modalidade semipresencial se diferencia do modelo convencional de ensino, onde são observadas divergências em carga horária e disciplinas ofertadas. Quanto à dinâmica da disciplina de Química Geral, esta funciona com ferramentas básicas disponibilizadas pelo Moodle, como: fóruns, chats, glossário, entre outros. A frequência de participações dos tutores nos três polos foi baixa quando comparadas as participações dos alunos que apresentaram considerável atuação. As matrizes curriculares revelam que as duas modalidades possuem suas especificidades no qual o tutor não apresenta eficiência na atuação dos fóruns virtuais.

\section{DYNAMICS OF A GENERAL CHEMISTRY DISCIPLINE AT A TECHNICAL COURSE SEMIPRESENTIAL}

\begin{abstract}
The distance education brought several positive impacts due to the increase and accessibility to teaching, since student and teacher did not need to be present in the same physical place so that the exchange of knowledge happened. Thus, this study tries to compare two curricular matrices of teaching of the technical course in Chemistry in the modalities: presential and semipresential. In addition to verifying quantitatively the participation of tutors in virtual learning forums. As a methodological resource, a public educational institution was selected offering the technical course in chemistry. After analyzing the data it is possible to perceive that the
\end{abstract}

Technical course in Chemistry in the semipresential modality differs from the conventional model of teaching, where divergences in time load and offered disciplines are observed. As for the dynamics of the General Chemistry discipline, it works with basic tools provided by Moodle, such as forums, chats, glossary, among others. The participation of the tutors in the three poles was low when comparing the participations of the students who presented considerable performance. The curriculum matrices reveal that the two modalities have their specifics, in which the tutor does not have efficiency during the virtual forums.

KEYWORDS: ead, teacher, forum, moodle, performance 


\section{INTRODUÇÃO}

O termo ensino a distância remete a ação do professor de ensinar a distância, no qual basicamente não acontece, onde seu papel está voltado, essencialmente como articulador de informações, no entanto a utilização da expressão educação a distância (EaD) é mais abrangente e comumente utilizada, embora ambas não sejam corretamente apropriadas (MORAN, 2018, p.1). Para Preti (1996, p.43), o ensino é caracterizado pela instrução, socialização de informação, aprendizagem, entre outros. Enquanto, Maroto $(1995$, p.4) trata a educação como estratégia de formação humana, onde pensar, criticar, inovar e participar são consequências que levam os alunos a aprenderem a aprender, construindo sua própria estrutura cognitiva.

Nunes (1993, p.7) discorre que os primeiros conceitos de EaD estavam ligados a comparação referencial com o ensino convencional, não propondo assim uma definição específica para este tipo de ensino. Para Alves $(2011$, p.83) há diversas definições de EaD, onde cada autor define e enfatiza uma questão de interesse, porém todos apresentam pontos em comum. Logo, as tecnologias servem como um aparato para que possibilite uma comunicação a distância.

Saraiva (2010, p.29) enfatiza a importância da tecnologia no processo de ensinoaprendizado em EaD: "[...] os processos de ensino-aprendizagem no qual professor e aluno não compartilham o mesmo lugar simultaneamente, necessitando que sua relação seja mediada por algum tipo de tecnologia". Para Maia e Mattar (2007, p.6), a EaD é construída mediante o uso de tecnologias: "A EaD é uma modalidade de educação em que professores e alunos estão separados, planejada por instituições e que utiliza diversas tecnologias de comunicação".

Dessa forma, Cabanas e Vilarinho $(2007$, p.2) identificam a incerteza do tutor ser ou não ser professor, situando as barreiras e possibilidades de sua ação, o que pode fragilizar a EaD devido a dúvida. Assim, a necessidade de formação adequada desse personagem induz no desenvolvimento de capacidades da oportuna função de tutoria, em que o tutor é peça fundamental no ensino a distância, devido ao seu extenso papel pedagógico e contato rotineiro com estudantes.

Em ambientes de aprendizagem, seja em qualquer nível de ensino, a visão clássica de ensinar e aprender envolve a narrativa baseada no professor, onde apresenta conteúdos prontos e, aos alunos cabe o papel de copiar, memorizar, realizar avaliações e posteriormente esquecer o que mecanicamente se aprendeu. Porém, outras teorias de aprendizagem sugerem outras abordagens, uma vez que aprender mecanicamente seja perda de tempo (MOREIRA, 2013, p.43).

Conforme Prensky (2012, p.100) não se pode definir ao certo o que é aprendizagem, todavia a aprendizagem acontece quando o educando consegue reconhecer que está aprendendo. Embora, não haja uma definição concreta de aprendizagem, diversas teorias nos propõem como esse mecanismo acontece. As teorias de Ausubel sobre aprendizagem significativa, Moreira (2012, p.23) comenta que o fator mais importante para se ter uma aprendizagem significativa é incorporar novos conteúdos a partir do que o aprendiz já sabe, ou seja, os novos conhecimentos são organizados por meio da integração já estabelecida na estrutura cognitiva.

Driver e colaboradores (1999, p.31) afirmam que o conhecimento deve ser construído pelo aluno, não transmitido diretamente. Essa ideia defendida pelo construtivismo integrada a atividades que desafiem seu intelecto desperta assim ao ato de pensar, levando o aluno a buscar conhecimentos já estabelecidos, construindo possíveis soluções. Freire (1996, p.50), diz que os 
professores devem estar conscientes do seu papel na educação, que ensinar não é transmitir conhecimento, ensinar é ser capaz de estimular o aluno na descoberta de novas possibilidades sociais, de modo que toda a bagagem cognitiva contida pelos educandos seja aproveitada pelo professor.

De fato, a educação contribui significativamente para o processo de pesquisa e transformação da sociedade, uma vez que educação e pesquisa estão interligadas de modo a compreender e estudar as modificações do mundo, onde o campo de conhecimento envolvendo as ciências exatas e da terra propõem uma explicação analítica que tenta explicar os fenômenos do dia a dia. Sendo a Química, uma ciência que estuda a matéria e suas transformações na perspectiva atômica, como também uma ciência experimental, que possibilita ampliação do saber em diversos campos de estudo, onde esta área se torna indispensável para contribuir em situações que levem a melhoria da qualidade de vida (CLEMENTINA, 2011, p.37; CARDOSO; COLINVAUX, 2000, p.402).

O estudo de Química deve desenvolver a capacidade de pensar, analisar, experimentar e buscar explicações para o que se lê ou se vê, no intuito de compreender e refletir sobre os acontecimentos que rodeiam a natureza do conhecimento científico e coloquial (DRIVER et al., 1999, p.37). Dentre os problemas, que levam ao baixo índice de aprendizado, bem como, ao desinteresse pelos conteúdos de Química, considerando-o sem importância relacionam-se a: abstração dos conteúdos, memorização de nomes e fórmulas, além da falta de contextualização. Esses são alguns fatores que, também (ROSA; TOSTA, 2005, p.255). SCHNETZLER (2002, p.20) acredita que uma das principais dificuldades para a construção do conhecimento em Química está na transformação conjunta dos pensamentos científicos em competências didáticas, o que torna o ensino dessa ciência mais apropriado.

Aos olhos da $\mathrm{EaD}$, o material pedagógico deve ser bem elaborado e adequado para o nível cognitivo do aluno, para que a aprendizagem seja simples e significativa. Ao relacionar a aprendizagem na EaD, Carvalho, Nevado e Menezes (2005, p.4) salientam a importância de arquitetar o saber com propostas que levem os estudantes a desenvolverem a capacidade de autonomização da aprendizagem. Sales (2005, p.6) argumenta que o material didático em EaD deve ser articulado e bem direcionado, onde a utilização destas ferramentas deve alcançar consideráveis índices de aprendizagem, uma vez que bem utilizada pelo professor/tutor.

A importância da relação professor-aluno promove a visão do professor em descobrir as dificuldades encontradas pelos alunos, vivenciando situações diferentes e, com isso proferindo ferramentas didáticas eficientes, uma vez que esta adequação é indispensável no ensino a distância. Visto que, a Química é uma ciência experimental, há a possível falta de aulas práticas rotineiras na EaD. Embora que encontros presenciais tentem sanar a defasagem muitas vezes acabam não sendo eficientes para a construção de um conhecimento prático (GONÇALVES; MARQUES, 2016, p.226). Porém, Bottentuit Junior e Coutinho (2007, p.9), evidenciam que o uso de softwares educacionais relacionados a aulas práticas de Química, são eficazes para um direcionamento prático dos conteúdos de Química, contanto que sejam bem utilizadas pelo tutor.

As ferramentas disponibilizadas pelo ambiente virtual de aprendizagem (AVA), seja síncrona (comunicação momentânea entre os envolvidos) ou assíncrona (comunicação não momentânea entre os envolvidos) auxiliam e gerenciam o aprendizado do aluno, contanto que sejam bem organizadas, onde seu foco concebe facilitar o entendimento do estudante perante os 
conteúdos, além de promover discussões em grupo em meio a atividades colaborativas (MONTES; LINS, 2015, p.108).

Se tratando dos ambientes virtuais de aprendizagem, Trindade e Fiolhais (1996, p.12), encaram a aprendizagem virtual por meio de aspectos relacionados a participação efetiva do aluno e interações com os ambientes construídos. No qual, o ensino e aprendizagem de Química é construído pelos alunos e auxiliado pelo tutor utilizando temas transversais, como: ciclo da água, constituição do dióxido de carbono, produção da margarina, entre outros assuntos que tornem o ensino de Química um ponto subsequente e inacabado.

Os ambientes virtuais de aprendizagem, exemplo, o Moodle surgiu para dar apoio à formação online. As plataformas conduzem a disponibilização de diferentes recursos didáticos como hipertextos, vídeos, áudios, artigos científicos, sítios, avisos e registros de atividades, entre outros, além de conceder ferramentas (blog, chat, wiki, fórum, dicionário e outros) que auxiliam o aprendizado. Diante das atividades realizadas pelos alunos, o professor pode e deve disponibilizar um comentário a cada aluno, seja por ferramentas síncronas como chats online ou ferramentas assíncronas auxiliando os debates em fóruns de discussão, este último contribuindo para a construção e desenvolvimento da aprendizagem colaborativa (CARVALHO, 2007, p.30).

Stahl, Koschmann e Suthers (2006, p.55) retratam a aprendizagem colaborativa como uma área das ciências que estuda o aprendizado das pessoas por meio de grupos podendo ser mediada por computadores, através de negociações e compartilhamento de ideias relevantes à resolução de problemas. Dias $(2004$, p.4) ressalta que os processos e estratégias colaborativas encorajam os alunos ao trabalho de equipe no intuito de engrandecer o conhecimento e construir a aprendizagem, além da necessidade de orientação de um modelo de discussão que alimente a participação dos estudantes.

Sousa $(2014$, p.58) retrata o fórum de maneira geral, como um espaço ou ambiente em que qualquer assunto possa ser debatido, questionado, julgado e executado, estabelecendo um diálogo entre os envolvidos, ou seja, um local que pensamentos são expostos e discutidos, onde opiniões podem ser acrescentadas ou retraídas a fim de agregar ou alterar ideologias. Sánchez (2005, p.2) define fóruns de aprendizagem como:

[...] um espaço de comunicação formado por quadros de diálogo nos quais se inclui mensagens que podem ser classificadas tematicamente. Nestes espaços, os alunos podem realizar contribuições, esclarecer outras, refutar as dos demais participantes, etc., de uma forma assíncrona, sendo possível que as contribuições e mensagens permaneçam todo o tempo à disposição dos demais participantes.

Todavia as contribuições efetuadas durante fóruns de aprendizagem devem ser devidamente elaboradas para que promovam um debate expressivo e amplie os conhecimentos dos estudantes, ficando o professor-tutor atento aos possíveis plágios, comentários sem embasamentos e/ou sem importância científica, pois não contribuem para efetivação do aprendizado ou intercâmbio de pensamentos (AZEVEDO; REATEGUI; BEHAR, 2009, p.41).

\section{MATERIAIS E MÉTODOS}

A classificação da técnica consiste do tipo documental e estudo de caso que, segundo Gil (2009, p.44) baseia-se em examinar uma fonte rica e estável de dados, não existindo contato com os sujeitos da pesquisa, além de haver um estudo profundo de um ou poucos objetos, onde os 
limites estão claramente definidos. A abordagem investigativa apresenta característica quantitativa, utilizando como fonte de dados a frequência das participações de alunos e tutores durantes os fóruns além da necessidade de análise comparativa entre duas grades curriculares entre cursos técnicos em Química na modalidade presencial e na modalidade semipresencial.

Por meio de autorização prévia da coordenação do curso foi cedido acesso a matriz curricular dos cursos, a plataforma Moodle, bem como os conteúdos da disciplina, para retirada de componentes interessantes para este estudo. Outros dados de interesse foram retirados do sítio da instituição. Investigaram-se os fóruns da disciplina de Química Geral, ministrada no primeiro semestre do curso. Os fóruns analisados possuíam os seguintes conteúdos: Matéria e Energia (Fórum 1), Modelo atômico e Tabela periódica (Fórum 2), Ligações Química (Fórum 3), Funções Químicas Inorgânicas (Fórum 4), Reatividade Química dos Ácidos (Fórum 5), Reações Químicas e Estequiometria (Fórum 6) e Equilíbrio Químico (Fórum 7).

A partir da matriz curricular e atividades disponibilizadas pelo curso, realizou-se uma análise descritiva do funcionamento do curso e disciplina, comparando-o a um curso técnico em Química presencial concomitante. Os dados foram exibidos em formato de tabela e figuras, para avaliação quantitativa dos dados, calculou-se manualmente repetidas vezes a frequência de participação de tutores e alunos em todos os fóruns virtuais. Em seguida, os dados foram analisados e os resultados são mostrados na forma de gráficos. A coleta de alunos matriculados foi realizada no sítio da instituição de ensino, onde procurou-se quantificar o total de alunos ativos, ou seja, o total de estudantes matriculados no curso Técnico em Química no período de oferta da disciplina de Química Geral.

\section{RESULTADOS E DISCUSSÃO}

\subsection{Análise do funcionamento do curso Técnico em Química Semipresencial}

O curso técnico em Química na modalidade semipresencial apresentou carga horária total de 1200 horas, divididas em 23 disciplinas, no qual se somou 60 créditos, onde todas as disciplinas disponibilizadas apresentam caráter obrigatório, ou seja, em todas, o aluno deve ter alcançando aprovação para a obtenção do título.

O curso técnico em Química na modalidade presencial apresentou carga horária total de 1600 horas, divididas em 31 disciplinas, onde exibe 73 créditos obrigatórios e 07 créditos optativos, ou seja, são oferecidos 80 créditos no somatório total. Para obtenção do título de técnico em Química nesta modalidade, faz-se necessário o estudante cumprir as disciplinas obrigatórias que resulta em uma carga horária total de 1460 horas. 


\begin{tabular}{|c|c|c|c|c|c|c|c|}
\hline & \multicolumn{3}{|c|}{ Técnico em Quimica na modalidade a semipresencial } & & \multicolumn{3}{|c|}{ Técnico em Química na modalidade presencial } \\
\hline & Disciplinas & Créditos & $\mathrm{CH}$ & & Disciplinas & Créditos & $\mathrm{CH}$ \\
\hline \multirow{6}{*}{$\begin{array}{l}S \\
1\end{array}$} & Matemática Aplicada & 02 & 40 & \multirow{8}{*}{$\begin{array}{l}S \\
1\end{array}$} & Noções de Empreendedorismo & 02 & 40 \\
\hline & Química Geral & 04 & 80 & & Quimica Geral & 04 & 80 \\
\hline & Laboratório de Química & 02 & 40 & & Laboratório de Química & 03 & 60 \\
\hline & Química Orgânica & 04 & 80 & & Matemática Aplicada I & 03 & 60 \\
\hline & Informática Aplicada & 02 & 40 & & Biologia & 02 & 40 \\
\hline & Proteç̃o Ambiental & 02 & 40 & & Proteção Ambiental & 02 & 40 \\
\hline \multirow{6}{*}{$\begin{array}{l}S \\
2\end{array}$} & Química Analitica Quantitativa & 04 & 80 & & Física Aplicada & 02 & 40 \\
\hline & Físico-Química & 04 & 80 & & Informática Aplicada & 02 & 40 \\
\hline & Higiene e Segurança no Trabalho & 02 & 40 & \multirow{9}{*}{$\begin{array}{l}\mathrm{S} \\
2\end{array}$} & Química Orgânica & 04 & 80 \\
\hline & Planejamento e Controle da & 02 & 40 & & Mecânica dos Fluidos & 02 & 40 \\
\hline & Produção & & & & Termodinâmica & 03 & 60 \\
\hline & Fisica Aplicada & 02 & 40 & & Matemática Aplicada II & 02 & 40 \\
\hline \multirow{6}{*}{$\begin{array}{l}\mathrm{S} \\
3\end{array}$} & Processos Químicos Orgânicos I & 02 & 40 & & Higiene e Segurança do Trabalho & 02 & 40 \\
\hline & Logistica Industrial & 02 & 40 & & Planejamento e Controle da & 03 & 60 \\
\hline & Operações Unitárias I & 02 & 40 & & Produção & & \\
\hline & Gestão da Qualidade & 02 & 40 & & Instrumento $\mathrm{e}$ Controle & 02 & 40 \\
\hline & Instrumentação e Controle & 02 & 40 & & Microbiologia Geral & 02 & 40 \\
\hline & Microbiologia Geral & 04 & 80 & \multirow{6}{*}{$\begin{array}{l}S \\
3\end{array}$} & Físico-Química & 03 & 60 \\
\hline \multirow{17}{*}{$\begin{array}{l}S \\
4\end{array}$} & Análise Instrumental & 04 & 80 & & Processos Químicos Orgânicos I & 03 & 60 \\
\hline & Operações Unitárias II & 02 & 40 & & Logistica Industrial & 02 & 40 \\
\hline & Processos Químicos Orgânicos II & 02 & 40 & & Operações Unitárias I & 02 & 40 \\
\hline & Tratamento de Residuos e Efluentes & 04 & 80 & & Gestão da Qualidade & 02 & 40 \\
\hline & Tratamento de Água para a Indústria & 02 & 40 & & Análise Química Quantitativa & 04 & 80 \\
\hline & Noç̃̃es de Empreendedorismo & 02 & 40 & \multirow{9}{*}{$\begin{array}{l}S \\
4\end{array}$} & Análise Instrumental & 03 & 60 \\
\hline & TOTAL & 60 & 1200 & & Operações Unitárias II & 02 & 40 \\
\hline & & & & & Tecnologia do Biodiesel & 02 & 40 \\
\hline & & & & & Tratamento de Residuos e Efluentes & 02 & 40 \\
\hline & & & & & Corrosão & 02 & 40 \\
\hline & & & & & Tratamento de Água para a Indústria & 02 & 40 \\
\hline & & & & & Avaliação Econômica dos Processos & 02 & 40 \\
\hline & & & & & Quimicos & & \\
\hline & & & & & Microbiologia Industrial & 02 & 40 \\
\hline & & & & \multirow[t]{3}{*}{$\begin{array}{l}S \\
5\end{array}$} & $\begin{array}{l}\text { Trabalho de Conclusão de Curso - } \\
\text { TCC }\end{array}$ & 07 & 140 \\
\hline & & & & & TOTAL - Obrigatórias & 73 & 1460 \\
\hline & & & & & TOTAL - Todas Disciplinas & 80 & 1600 \\
\hline
\end{tabular}

Figura 1. Matriz curricular curso técnico em Química semipresencial e presencial.

Observando a Figura 1, percebe-se a divergência na carga horária entre as duas modalidades educacionais, presencial e semipresencial, bem como as disciplinas oferecidas em cada estrutura curricular. A distinção curricular compactua para uma formação muitas vezes fragmentada ou pontual, devido à formação distinta que é alcançada por cada estudante adepto a uma das modalidades. Dessa forma, uma instituição de ensino ofertante do mesmo curso deve oferecer aos seus discentes uma formação igualitária e sem distinções, uma vez que as duas modalidades apresentam tais desigualdades em seus currículos.

O currículo está frequentemente associado aos conteúdos a serem estudados. $\mathrm{Na}$ EaD, os currículos devem ser planejados e adaptados para que o aprendizado seja extraído ao máximo. Quando comparado ao ensino convencional, os currículos "virtuais" estão muitas vezes articulados na maneira que acontecerá o repasse dos conteúdos e não na quantidade de disciplinas a serem trabalhadas, o que também é enfatizado por Otero (2012).

Pinto e Andrade (2014, p.87) ao analisarem o currículo de quatro cursos superiores a distância, observaram a divergência em suas estruturas curriculares, onde cada instituição apresenta um foco diferente em seus currículos. O curso técnico em Química citado neste trabalho está voltado para a aplicação prática e direcionada, por meio de conceitos técnicos e diretos. A 
ampliação do saber científico está constantemente relacionada a alguns fatores: estrutura curricular, posição didática do professor, bem como interligada a autonomia do aluno.

Behar (2009, p.39) destaca que o padrão educacional que vigora, relaciona o ensino tecnicista na função de preparar o estudante em papéis específicos, de acordo com suas aptidões psicomotoras. Neste seguimento, as práticas pedagógicas do ensino técnico não garantem o aperfeiçoamento de conhecimentos ligados à contextualização e incentivo pela curiosidade dos alunos. Para Silva (2011, p.7), mas também Aires e Lambach (2010, p.12), a curiosidade e contextualização no ensino de Química proporcionam a busca e compreensão dos acontecimentos de forma rica e prazerosa, pois tais eixos educacionais facilitam a abrangência do saber.

A ausência de algumas disciplinas no curso técnico em Química semipresencial, como: Biologia, Mecânica dos Fluídos, Termodinâmica, Matemática Aplicada II, Tecnologia do Biodiesel, Corrosão, Avaliação Econômica dos Processos Químicos, Microbiologia Industrial e Trabalho de Conclusão de Curso, podem acarretar na falta de uma formação completa. Por outro lado, essa lacuna no currículo pode gerar um aproveitamento mais significativo das outras disciplinas, já que a carga horária não se torna muito elevada.

Um ponto em destaque diz respeito à falta de disciplinas relacionadas a adaptação da modalidade a distância, pois engloba conceitos ligados a EaD, bem como as ferramentas utilizadas nesta modalidade, como também ressalta objetivos pertinentes de como se estudar a distância. Em virtude da importância relacionada às disciplinas introdutórias para ambientação das plataformas online, Martins e Cruz (2009, p.17) relataram que a disciplina de Introdução a EaD deve ser oferecida no primeiro semestre do curso, onde seu objetivo deve atingir aspectos básicos da EaD e habituar os estudantes em situação de aprendizagem individual e colaborativa. Dessa forma, a disciplina poderá proporcionar ao estudante um melhor aproveitamento durante todo o curso.

É importante destacar que por se tratar da instituição de ensino que proporciona a oferta de um curso similar com modalidades diferentes, torna-se necessário a utilização da grade curricular semelhante, todavia a divergência entre os dois currículos está na inserção de disciplinas que justificam e esclarecem a EaD. Sendo assim, uma disciplina como Introdução a EaD torna-se altamente necessária visto que irá habituar o aluno sobre o semblante que rodeia o ensino a distância, bem como a plataforma virtual de aprendizagem utilizada no decorrer do curso.

A plataforma Moodle disponibiliza para o tutor diversas ferramentas (Figura 2) que auxiliam o aprendizado do aluno durante o decorrer do curso. A versatilidade do uso das ferramentas no ensino pode proporcionar uma aprendizagem mais significativa e colaborativa, uma vez que utilizadas corretamente para alcançar o desenvolvimento cognitivo do estudante. Ferramentas como Chats, Fóruns e Wikis são instrumentos ímpares para a ampliação da aprendizagem colaborativa, visto que esses mecanismos necessitam de participação de um grupo de estudantes para que aconteça a aprendizagem, seja de forma síncrona ou assíncrona, variando conforme os objetivos pré-estabelecidos que o tutor queira atingir.

As ferramentas de interações mútuas como é o caso do wiki, fórum e mensagens (e-mail) intensificam a interação dos usuários participantes, onde os conhecimentos vão sendo lapidados de forma gradativa, além de proporcionar uma aproximação pessoal entre os envolvidos, fato apresentado por Lawinscky e Haguenauer (2011, p.9). Já a ferramenta chat, no que lhe concerne, promove uma aproximação imediata, síncrona, onde alunos e professores se comunicam 
momentaneamente, seja tirando dúvidas relacionadas ao conteúdo ou promovendo relações interpessoais.

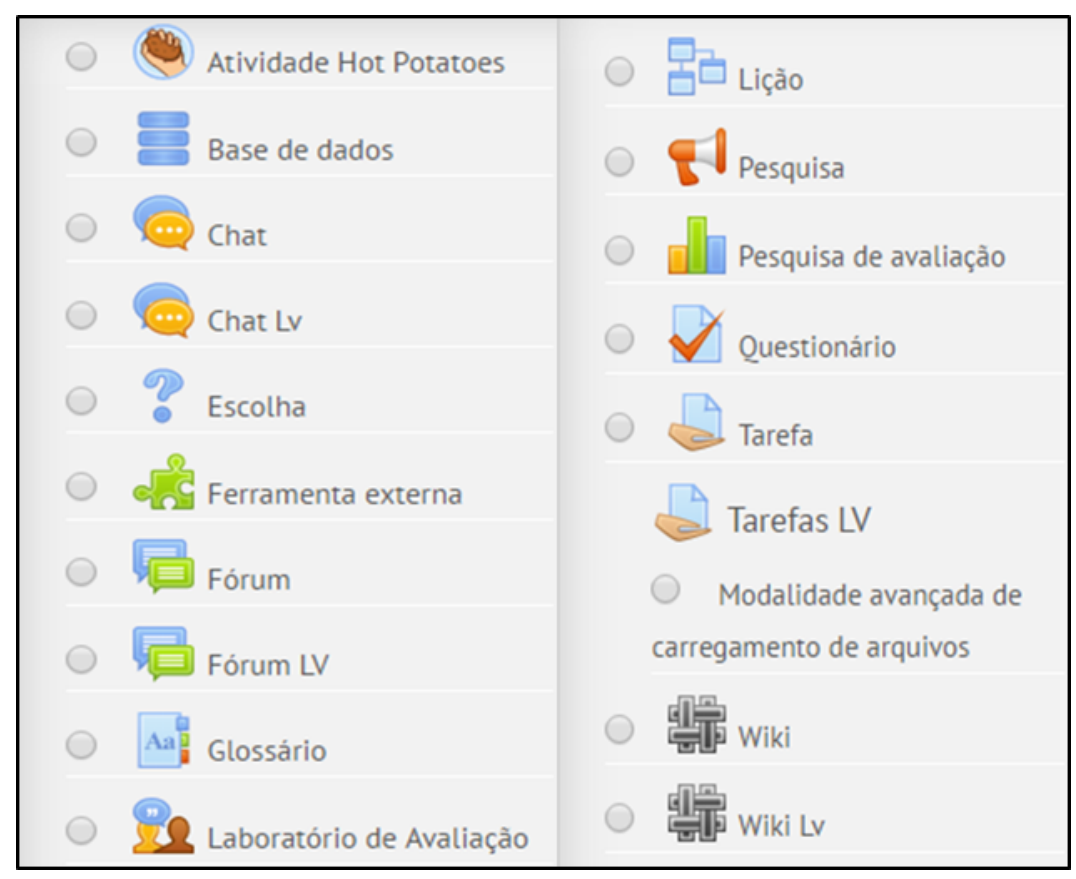

Figura 2. Ferramentas pedagógicas disponibilizadas pelo Moodle.

Devido à natureza assíncrona de algumas ferramentas dispostas nos AVA's, o educando consegue se apropriar de informações sem a necessidade de respostas momentâneas e prontas. Aragão (2004, p.347), retrata que as ferramentas assíncronas concedem ao aluno a possibilidade de aumentar a qualidade e aprofundamento de textos relacionados aos conteúdos estudados, em razão ao tempo de pesquisa ser maior para exposição dos conhecimentos adquiridos, diferentemente das ferramentas síncronas, onde a resposta deve ser imediata.

Já, a disciplina de Química Geral, apresentou como componentes básicos para realização do curso ferramentas como: Tarefa, Fórum, Chats, Material Complementar e Glossário (Figura 3). $\mathrm{Na}$ disciplina não foram utilizados instrumentos pedagógicos como: Wiki, Questionário, entre outros. 


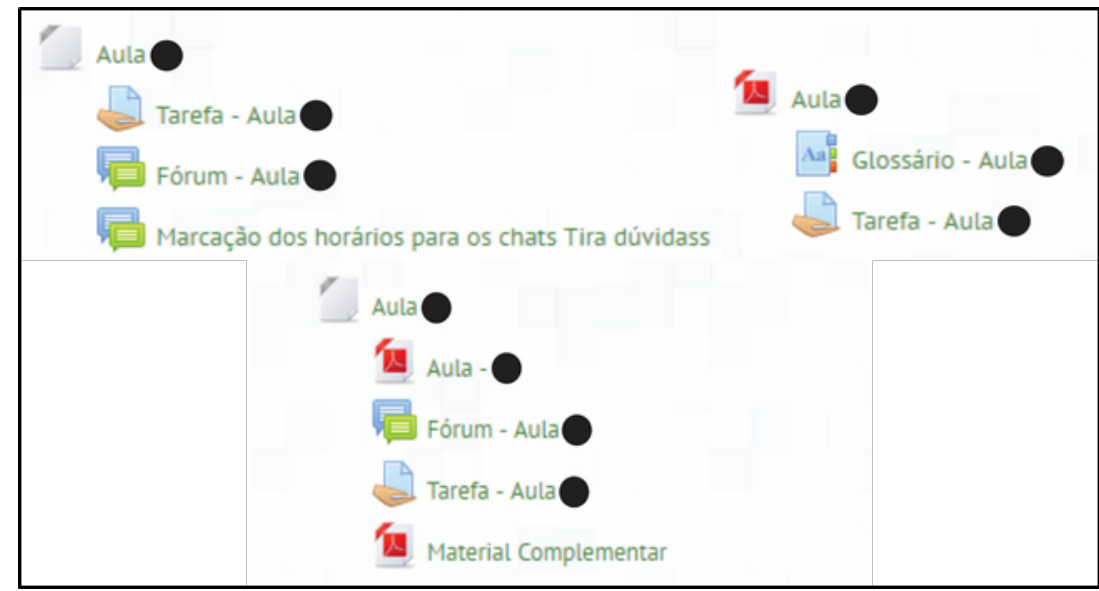

Figura 3. Ferramentas pedagógicas utilizadas pelos tutores durante o curso de Química Geral.

O uso de uma ou várias ferramentas em um ambiente de aprendizagem pode apresentar características positivas e/ou negativas. Desde que organizadas de maneira contínua e condicional, estes instrumentos pedagógicos devem atingir o aluno a ponto de aperfeiçoar sua compreensão em assuntos relacionados ao módulo de estudo. Pavezi e colaboradores $(2011$, p.6) expõem em sua pesquisa que muitos dos estudantes adeptos da EaDrelatam que as ferramentas mais importantes nos AVA's são vídeos aulas, materiais complementares e fóruns, pois promovem maior eficiência no aprendizado.

Hamawaki e Pelegrim (2009, p.89) completam que as vídeos aulas promovem maior mobilidade e flexibilidade para o estudo, uma vez que venham acompanhadas de orientações e sugestões complementares para maior exploração educativa. Tal exploração educacional é relacionada com os fóruns de discussão virtual, onde as dinamizações entre os envolvidos favorecem o processo de ensino e aprendizagem, por meio de contribuições interessantes e globais discutidas nesse ambiente.

No que diz respeito à disciplina de Química, o uso de diferentes ferramentas pode auxiliar na compreensão de conteúdos que exigem maior atenção e assiduidade dos alunos, já que a Química é vista pelos educandos como uma ciência abstrata. Porém, não adianta utilizar diversas ferramentas de aprendizagem se o objetivo não for alcançado. Desta forma os instrumentos utilizados na oferta da disciplina (Fórum, Chat, Glossário, Tarefa e Material Suplementar) oferecem aos alunos considerável aparato pedagógico, contanto que o tutor e o aluno participem ativamente dos trâmites que acontecem durante o processo de aprendizagem.

Suarez e Desaulniers (2001, p.2) ao analisar uma disciplina de Química geral, em um curso de Engenharia Química à distância reportam que a proposta curricular tem caráter teórico-prático. O uso das atividades teóricas no curso englobou a utilização de hipertextos, vídeo conferências e exercícios individuais e coletivos. Enquanto que as atividades laboratoriais possuíram uma dinâmica virtual e presencial, ambas orientadas por tutores. Os autores afirmam que tais recursos didáticos promoveram a interação e participação efetiva dos alunos, onde o tutor consegue alcançar os alunos afastados das atividades propostas.

Tavares, Souza e Machado (2010, p.4) apresentam uma proposta metodológica para facilitar a aprendizagem do ensino prático de Química, no qual ferramentas como: fóruns, chats, glossários, diários, entre outros são utilizadas e adaptadas para garantir o conhecimento a ser 
adquirido pelo aluno. O potencial conjunto dos objetos virtuais de aprendizagem demonstra importante contribuição para o desenvolvimento cognitivo do aluno devido suas particularidades e, principalmente por consolidar laboratórios virtuais, que dinamizam o aprendizado em Química.

\subsection{Participação nos Fóruns - Estudo Quantitativo}

Na Figura 4a, são mostrados os quantitativos das informações dos alunos e tutor do Polo 1, que no primeiro fórum dos alunos, são elevados (56), porém nos fóruns seguintes a frequência de participação dos alunos decresce consideravelmente. O tutor pouco colabora nas discussões dos fóruns, pois sua contribuição durante o decorrer da disciplina corresponde a $10,1 \%$ do total. Ficando evidente também sua ausência nos fóruns 2, 6 e 7.

$\mathrm{Na}$ Figura 4b, são apresentadas as participações dos alunos e tutor do Polo 2. A frequência das é baixa, quando comparadas com o Polo 1, onde é possível perceber que a frequência de respostas dos alunos do Polo 2 foi inferior a 30 postagens em média. Percebe-se que durante 0 primeiro fórum foram contabilizadas 28 postagens dos estudantes, onde o quantitativo foi diminuindo, chegando a 18 postagens no fórum 5 . O tutor contribuiu com três postagens no fórum 1 , e ausentou-se nos fóruns seguintes.

A Figura 4c, faz referência ao Polo 3, onde o maior quantitativo de contribuições dos estudantes foram de 36 em cada fórum. Nos fóruns seguintes, as participações decaíram chegando ao menor número (19), no fórum 7. O tutor participou 9 vezes distribuídas em 5 fóruns, porém não houve participações nos fóruns 3 e 4 .

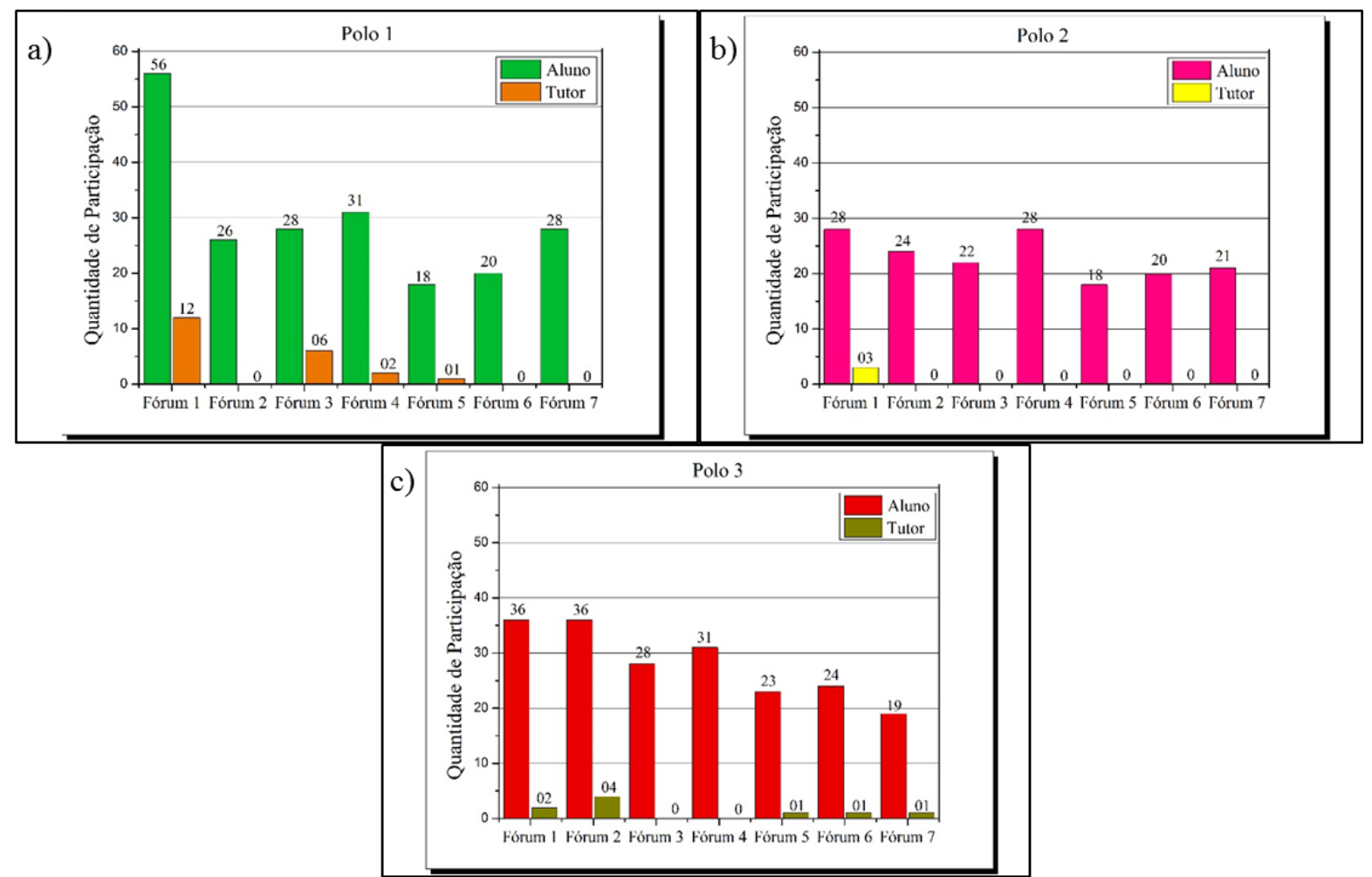

Figura 4. Quantidade de participação de tutor e alunos: (a) Polo 1, (b) Polo 2 e (c) Polo 3. 
A frequência de alunos matriculados que utilizaram a plataforma Moodle na disciplina de Química Geral é expressa na Tabela 1:

Tabela 1. Alunos matriculados na disciplina de Química Geral em cada Polo.

\begin{tabular}{c|c}
\hline Polo & Alunos Matriculados \\
\hline 1 & 29 \\
\hline 2 & 36 \\
\hline 3 & 32 \\
\hline
\end{tabular}

A quantidade de participações dos alunos nos fóruns virtuais é consideravelmente mediana nos três polos visto que, a quantidade de alunos matriculados na disciplina não expressa o percentual de debates que deveriam tem ocorrido (Tabela 1). Todavia, executando uma leitura crítica percebe-se que as comunicações entre os estudantes demonstram qualidade na escrita, bem como indagações relacionadas aos temas propostos pelos fóruns, embora apresentem aspectos de imitação. A atuação do tutor interfere inteiramente no processo dialógico estabelecido pelos estudantes, no qual seu incentivo promove o aumento das discussões durante a realização das atividades propostas.

Mortimer e Scott (2016, p.291) consideram que as interações entre professores e alunos no ensino de Ciências envolvem dois extremos. O primeiro leva em consideração as ideias e interrelações estabelecidas durante o processo de aprendizagem, ou seja, o estudante é o sujeito ativo das interações, apresentando propostas e idealizando novos dilemas. No segundo extremo, o estudante atua como um repetidor dos conhecimentos científicos "aprendidos", onde as abordagens pessoais e novas ideais não são levadas em consideração durante o processo.

Vigneron $(2003$, p.57) considera que os fóruns virtuais são elementos essenciais na EaD, pois essas ferramentas contêm a capacidade de retirar o aluno do isolamento em razão dos educandos participarem ativamente de debates a serem originados neste espaço. Portanto, a correta administração e envolvimento do tutor nas atividades a serem realizadas contribuem para a produção científica esperada nos fóruns virtuais.

As médias de participação dos estudantes nos setes fóruns, conforme a Figura 4, foram: 29,57 (Polo 1); 23,00 (Polo 2); 28,14(Polo 3). Percebe-se um pequeno desvio entre as médias, contudo é perceptivo a baixa participação dos estudantes no Polo 2, como comentado anteriormente. É sabido que no decorrer dos fóruns o baixo percentual de participação dos alunos pode estar relacionado a diversos fatores, dentre os quais podem se destacar a desistência do aluno da disciplina, pouco incentivo do tutor, bem como a falta de acessibilidade à internet. No entanto, não foi diagnosticada nenhuma desistência formal, junto à coordenação do curso, por parte dos alunos ficando evidente o essencial papel do tutor na busca e identificação de possíveis evasões no decorrer da disciplina

A baixa interação dos tutores exibidas nos três polos (Figura 4) acarretam por influenciar no baixo índice de discussão envolvendo os estudantes, visto que o tutor é o incentivador desse processo. A relativa participação dos estudantes nos fóruns pode ser justificada na obrigatoriedade 
do uso da ferramenta, todavia com um índice elevado de atuação do tutor, este contribuiria para a efetivação e aprimoramento do instrumento pedagógico que é o fórum.

Boa parte dos usuários adeptos aos fóruns virtuais não possuem uma formação adequada para o uso dessas ferramentas, onde os tutores devem ser orientados sobre a importância e consequências geradas sobre esses instrumentos que ajudas no desenvolvimento da EaD. Dotta e Giordan (2006, p.8) conferem que a formação e conhecimentos adequados das ferramentas computacionais, como os fóruns, interferem consideravelmente na atuação do educador, ou seja, o uso e pesquisa nos primeiros momentos de formação dos tutores contribuem para sua própria aprendizagem, como também influenciam diretamente na atuação como educador.

Sobre a formação do professor em EaD, Vigneron (2003, p.22) considera-se que um dos primeiros passos está na conscientização das dificuldades e possibilidades encontradas nessa modalidade de ensino, onde o preparo tecnológico, baseado em novas perspectivas da comunicação e informação, acaba gerando consequências pedagógicas em sua postura. A associação dos acontecimentos químicos envolvendo o cotidiano dos alunos são artifícios que desencadeiam a integração do desenvolvimento cognitivo dos educandos, visto que aliar os conceitos teóricos a fenômenos diários possibilita ao estudante realizar conexões que promovem o entendimento, assim como sugere a teoria de aprender significativamente.

Realizando o somatório das participações dos alunos em cada fórum, nos três polos, é possível observar que as maiores presenças estão nos fóruns 1, 2 e 4, respectivamente, abordando temas como química ambiental, chuva ácida e propriedades periódicas dos elementos. Tal efetividade de frequência dos alunos pode ser justificada pelo direcionamento proporcionado por cada fórum, onde a ideia de contextualizar os conteúdos colabora para uma maior cooperação dos estudantes nas atividades sugeridas. Outro ponto a ser observado é que em todos os polos, o fórum 4 apresentou uma tendência ao aumento do número de postagens, isto confere que os estudantes tendem a recuperar o tempo perdido nos primeiros fóruns, já que o fórum 4 encontrase na metade da disciplina.

Cardoso e Colinvaux (2000, p.403) evidenciam que a Química é considerada uma ciência importante na vida pessoal e social dos alunos, onde eles conseguem evidenciar sua aplicação no dia a dia. Todavia, faz-se necessário que os conhecimentos aprendidos em sala de aula ou em ambientes virtuais sejam refletidos em entendimentos associados aos acontecimentos químicos diários. Greca e Santos (2005, p.43) completam que nos conteúdos de Química há a possibilidade de coexistir diferentes conceitos ligados a outros seguimentos do saber, onde disciplinas como Física, Biologia, Matemática, entre outras, podem complementar os entendimentos químicos que rodeiam os princípios educacionais.

\section{CONSIDERAÇÕES FINAIS}

De fato, o ambiente virtual deve possuir o aparato necessário para que o aluno seja capaz de se sentir sensibilizado pelo o que será proposto no módulo a ser estudado. Para tanto, a plataforma Moodle oferece toda estrutura de ferramentas que promovem tais interações. 0 comparativo entre as grades curriculares nas duas modalidades (presencial/semipresencial) permitiu observar divergências relacionadas à carga horária total, encontrando um possível déficit na formação dos estudantes entre as duas modalidades. 
O uso das variadas ferramentas pedagógicas exibidas durante o curso de Química Geral não demonstra total eficiência, visto que o ambiente deve ser atrativo e diversificado para que o estudante não experimente de uma "mesmice" metodológica, onde os profissionais desse ambiente podem e devem se utilizar dessas ferramentas para a ampliação do saber científico e concretização do desenvolvimento cognitivo do aluno.

Durante os primeiros conteúdos estudados nos fóruns virtuais, a participação dos estudantes é efetiva, no entanto ao decorrer do curso as participações são menos frequentes. Os tutores se ausentam completamente durante alguns fóruns e participam poucas vezes de outros. A baixa participação dos tutores pode influenciar negativamente o aprendizado dos alunos e refletir na baixa participação dos estudantes no decorrer do curso.

Sendo assim, o caminho para uma educação mais igualitária no âmbito da EaD ainda é algo em constante construção. O uso correto e fundamentado das ferramentas virtuais de aprendizagem e a participação efetiva dos tutores podem diminuir consideravelmente o comparativo negativo ao analisar cursos em duas modalidades diferentes.

\section{REFERÊNCIAS BIBLIOGRÁFICAS}

Aires, J. A., \& Lambach, M. (2010). Contextualização do ensino de química pela problematização e alfabetização científica e tecnológica: uma possibilidade para a formação continuada de professores. Revista Brasileira de Pesquisa em Educação em Ciências, 10(1).

Alves, L. (2011). Educação a distância: conceitos e história no Brasil e no mundo. Revista Brasileira de Aprendizagem Aberta e a Distância, 10.

Aragão, C. R. D. (2004). A interatividade na prática pedagógica Online: Relato de uma experiência. Revista Educação e Contemporaneidade, 22(13), 341-351.

Azevedo, B. F. T., Reategui, E. B., \& Behar, P. A. (2009). Estudo de análise qualitativa em fórum de discussão. RENOTE: revista novas tecnologias na educação [recurso eletrônico]. Porto Alegre, RS.

Behar, P. A. (2009). Modelos pedagógicos em educação a distância. Artmed Editora.

Bottentuit Junior, J. B., \& Coutinho, C. P. (2007). Análise da usabilidade de um laboratório virtual de química orgânica.

Cabanas, C., \& Vilarinho, G. (2007). Educação a distância: tutor, professor ou tutor-professor. Rio de Janeiro: E-TIC 5o Encontro de educação e tecnologias da informação e comunicação.

Universidade Estácio de Sá, 1-18.

Cardoso, S. P., \& Colinvaux, D. (2000). Explorando a motivação para estudar química. Química Nova, 23(3), 401-404.

Carvalho, A. A. A. (2007). Rentabilizar a Internet no Ensino Básico e Secundário: dos recursos e ferramentas online aos LMS.

Carvalho, M. J. S., de Nevado, R. A., \& de Menezes, C. S. (2005, November). Arquiteturas pedagógicas para educação à distância: concepções e suporte telemático. In Brazilian Symposium on Computers in Education (Simpósio Brasileiro de Informática na Educação-SBIE) (Vol. 1, No. 1, pp. 351-360).

Clementina, C. M. (2011). A importância do ensino da química no cotidiano dos alunos do Colégio 
Estadual São Carlos do Ivaí de São Carlos do Ivaí-PR.

Dias, P. (2004). Desenvolvimento de objectos de aprendizagem para plataformas colaborativas. In Actas do VII Congreso Iberoamericano de Informática Educativa. Universidad de Monterrey, Monterrey (pp. 3-12).

Dotta, S., \& Giordan, M. (2006, November). Formação a distância de educadores para o diálogo virtual em serviços de tutoria on-line. In Brazilian Symposium on Computers in Education (Simpósio Brasileiro de Informática na Educação-SBIE) (Vol. 1, No. 1, pp. 11-20).

Driver, R., ASOkO, H., Leach, J., Mortimer, E., \& Scott, P. (1999). Construindo conhecimento científico na sala de aula. Química nova na escola, 9(5), 31-40.

Freire, P. (1996). Pedagogia da autonomia: saberes necessários à pratica educativa. São Paulo: Paz e Terra.

Gil, A. C. (2009). Como elaborar projetos de pesquisa. São Paulo: Atlas.

Gonçalves, F. P., \& Marques, C. A. (2016). Contribuições pedagógicas e epistemológicas em textos de experimentação no ensino de química. Investigações em Ensino de Ciências, 11(2), 219-238.

Greca, I. M., \& dos Santos, F. M. (2005). DIFICULDADES DA GENERALIZAÇÃO DAS ESTRATÉGIAS DE MODELAÇÃO EM CIÊNCIAS: O CASO DA FÍSICA E DA QUÍMICA (Difficulties in generalizing modelling strategies in science: the case of physics and chemistry). Investigações em Ensino de Ciências, 10(1), 31-46.

Hamawaki, M. H., \& Pelegrini, C. (2009). AS ferramentas do ensino à distância e suas contribuições para a eficácia no processo de aprendizagem do aluno. Revista CEPPG-N№ , 84-91.

Lawinscky, F. M., \& Haguenauer, C. (2011). Análise das ferramentas da plataforma MOODLE do LATEC/UFRJ segundo a abordagem sistêmico-relacional de interação. In CONGRESSO INTERNACIONAL DE EDUCAÇÃO A DISTÂNCIA (Vol. 17).

Maia, C., \& Mattar, J. (2007). ABC da EaD. São Paulo: Pearson Prentice Hall.

Maroto, M. L. M. (1995). Educação a Distância: aspectos conceituais. CEAD, ano, 2, 12-16.

Martins, A. S., \& Cruz, D. M. (2009). A EAD nas licenciaturas UFSC/UAB: um estudo comunicação e das interações na disciplina de Introdução a Educação a Distância. Contemporanea-Revista de Comunicação e Cultura, 6(2).

Montes, M. T., \& da Costa Lins, M. J. S. (2015). Colaboração como estratégia didática no fórum de discussão na graduação online. Cadernos de Pesquisa, 22(3), 100-114.

Moran, J. M. (2018). O que é um bom curso a distância. Visitado em, 20, 12.

Moreira, M. A. (2012). ORGANIZADORES PRÉVIOSE APRENDIZAGEM SIGNIFICATIVA (Advanced organizers and meaningful learning). APRENDIZAGEM SIGNIFICATIVA, ORGANIZADORES PRÉVIOS, MAPAS CONCEITUAIS, DIAGRAMAS V E UNIDADES DE ENSINO POTENCIALMENTE SIGNIFICATIVAS1, 30.

Moreira, M. A. (2013). Aprendizagem significativa, organizadores prévios, mapas conceituais, diagramas $V$ e unidades de ensino potencialmente significativas. Pontifícia Univerdidade Católica do Paraná.

Mortimer, E. F., \& Scott, P. (2016). Atividade discursiva nas salas de aula de ciências: uma ferramenta sociocultural para analisar e planejar o ensino. Investigações em ensino de ciências, 
7(3), 283-306.

Nunes, I. B. (1993). Noções de educação a distância. Revista educação à distância, 4(5), 7-25.

Otero, W. R. I. (2012). O currículo sob a ótica da educação a distância. In CONGRESSO INTERNACIONAL DA ASSOCIAÇÃO BRASILEIRA DE EDUCAÇÃO A DISTÂNCIA (Vol. 18).

Pavezi, A. M., Martins, C. Z., de Morais, L. L., de Souza, M. M. P., Lazilha, F. R., \& Goi, V. M. (2011). $O$ uso das ferramentas do ambiente virtual de aprendizagem pelos acadêmicos dos cursos de administração e processos gerenciais do NEAD-CESUMAR. In 17을 Congresso Internacional de Educação a Distância.

Pinto, S. C. M., \& Andrade, L. R. M. L. (2014). UMA ANÁLISE DOS CURRÍCULOS DE ADMINISTRAÇÃO EM EAD NO BRASIL: CURRÍCULO INSTRUCIONAL E HUMANÍSTICO. Revista Competência, 3(2).

Prensky, M. (2012). Aprendizagem baseada em jogos digitais. São Paulo: Editora Senac.

Preti, O. (1996). Educação a distância: inícios e indícios de um percurso. Universidade Federal de Mato Grosso. Instituto de Educaçao.

Rosa, M. I. P., \& Tosta, A. H. (2005). O lugar da Química na escola: movimentos constitutivos da disciplina no cotidiano escolar. Ciência \& Educação (Bauru).

Sales, M. V. S. (2005, May). Uma reflexão sobre a produção do material didático para EaD. In Anais do XII Congresso Internacional de Educação a Distância, ABED.

Sánchez, L. P. (2005). El foro virtual como espacio educativo: propuestas didácticas para su uso. Verista Quaderns Digitals Net, 40, 1-18.

Saraiva, K. (2010). Educação a distância: outros tempos, outros espaços. Ponta Grossa: Editora UEPG.

Schnetzler, R. P. (2002). A pesquisa em ensino de química no Brasil: conquistas e perspectivas. Química nova, 25(supl 1), 14-24.

Silva, M. (2001). Sala de aula interativa: a educação presencial e a distância em sintonia com a era digital e com a cidadania. Boletim Técnico do SENAC, 27(2), 1-20.

Sousa, H. D. M. (2014). Discurso direto e indireto: construção de sentido nos fóruns em educação a distância.

Stahl, G., Koschmann, T. D., \& Suthers, D. D. (2006). Computer-supported collaborative learning.

Suarez, P., \& Desaulniers, J. (2001). Uma experiência no ensino de química geral em curso a distância de graduação. In CONGRESSO INTERNACIONAL DE EDUCAÇÃO À DISTÂNCIA, VII. Disponível em: http://www. abed. org. br/congresso2001.

Tavares, J. M., Souza, A. C., \& Machado, A. L. (2010). EaD e ODA nas aulas práticas de química. In Simpósio Brasileiro de Educação Química, ABQ.

Trindade, J., \& Fiolhais, C. (1996). A realidade virtual no ensino e aprendizagem da Física e da Química. Gazeta de física, 19(2), 11-15.

Vigneron, J. (2003). Formação do docente em EAD. BARIAN PERROTTI, EM; VIGNERON, J. Novas Tecnologias no contexto educacional: reflexões e relatos de experiências. São Bernardo do Campo, SP: Umesp. 